\title{
Broadband Semielliptical Patch Antenna with Semicircular Ring Slot for WiMax Application
}

\author{
Brajraj Shrama, ${ }^{1}$ Vijay Sharma, ${ }^{2}$ K. B. Sharma, ${ }^{3}$ and D. Bhatnagar' \\ ${ }^{1}$ Microwave Laboratory, Department of Physics, University of Rajasthan, Jaipur 302004, India \\ ${ }^{2}$ Department of Physics, Government Mahila Engineering College, Ajmer 305002, India \\ ${ }^{3}$ Department of Physics, S.S. Jain Subodh P.G. College, Jaipur 302004, India
}

Correspondence should be addressed to Vijay Sharma; phyvijay@gmail.com

Received 24 January 2014; Revised 24 April 2014; Accepted 20 May 2014; Published 19 June 2014

Academic Editor: Samuel Ver Hoeye

Copyright (C) 2014 Brajraj Shrama et al. This is an open access article distributed under the Creative Commons Attribution License, which permits unrestricted use, distribution, and reproduction in any medium, provided the original work is properly cited.

\begin{abstract}
This paper reports the design and analysis of a semielliptical patch antenna modified by cutting semicircular ring slot in patch geometry and obtained results are discussed. The reported antenna is designed on a multilayered substrate material having two glass epoxy FR-4 substrates separated by a thin foam substrate having thickness $1.0 \mathrm{~mm}$. The size of ground plane is $75 \mathrm{~mm} \times 75 \mathrm{~mm}$, whereas the patch dimension along major and minor axes is $23.0 \mathrm{~mm}$ and $14.0 \mathrm{~mm}$, respectively. The two modes corresponding to resonance frequencies $3.39 \mathrm{GHz}$ and $3.73 \mathrm{GHz}$ are excited to provide wide impedance bandwidth $21.1 \%$ with respect to central frequency with stable radiation patterns. The antenna shows circular polarization with axial ratio bandwidth 5.5\% and minimum axial ratio value $1.65 \mathrm{dBi}$. The radiation patterns of proposed antenna are normal to the surface of patch and are almost identical in shape as required for practical applications. The proposed antenna covers entire median band of WiMax communication systems ranges from $3.40 \mathrm{GHz}$ to $3.6 \mathrm{GHz}$.
\end{abstract}

\section{Introduction}

Conventional microstrip antennas in general have a conducting regular shaped patch printed on a grounded microwave substrate and have the attractive features like low profile, light weight, easy fabrication, and low cost on mass production. However, microstrip antennas inherently have narrow bandwidth, low gain, and normally operate at a single frequency corresponding to their dominant mode $[1,2]$. For practical applications of these antennas, bandwidth and gain enhancement are usually demanded. With increasing demand of antennas for modern wireless communication systems, compact broadband planar antennas covering a wide frequency range are desired. Among the conventional patch geometries, microstrip antennas with rectangular, circular, or triangular shapes are extensively analyzed [2]. However patch shapes like elliptical patch are rarely touched upon by researchers perhaps due to the involvement of difficult mathematical modeling and involved boundary conditions during their analysis. The main advantage of elliptical patch is that circular polarization may be achieved more easily than in rectangular or circular patches. Looking at this benefit, several workers have analyzed regular elliptical patches but their realized impedance bandwidth was narrow [3-5]. Microstrip patches were recently modified to improve their performance either by inserting appropriate slot [6-8] or by increasing substrate thickness [9] or by using low permittivity substrate material [10] or by parasitic patches [11].

The wireless communication in India in general is limited to lower band $(2.50 \mathrm{GHz}$ to $2.69 \mathrm{GHz})$ and median band $(3.40 \mathrm{GHz}$ to $3.69 \mathrm{GHz})$ for WiMAX communication and hence the present work is targeted looking median band requirements. The dimensions of designed antennas are selected by considering this requirement. Considering frequency requirements, reverse calculations for conventional elliptical patch are performed to obtain the length of semimajor axis of patch (a) for the dominant mode of excitation $[12,13]$. Next by retaining same semimajor axis length we have converted conventional elliptical patch into a semielliptical patch antenna as overall size of later will be only half in comparison to that of conventional elliptical patch 


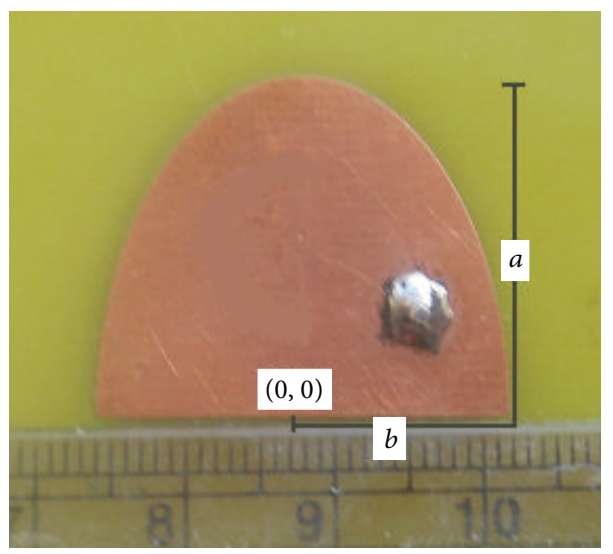

(a)

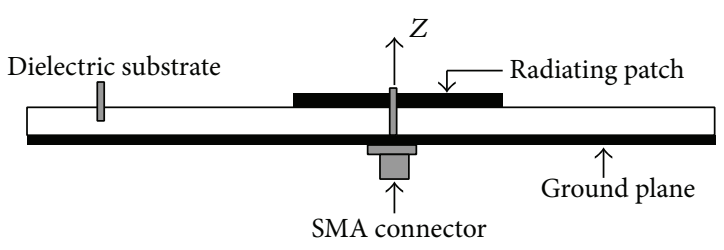

(b)

FIGURE 1: (a) Fabricated semielliptical patch antenna. (b) Side view of semielliptical patch antenna structure with feed arrangement.

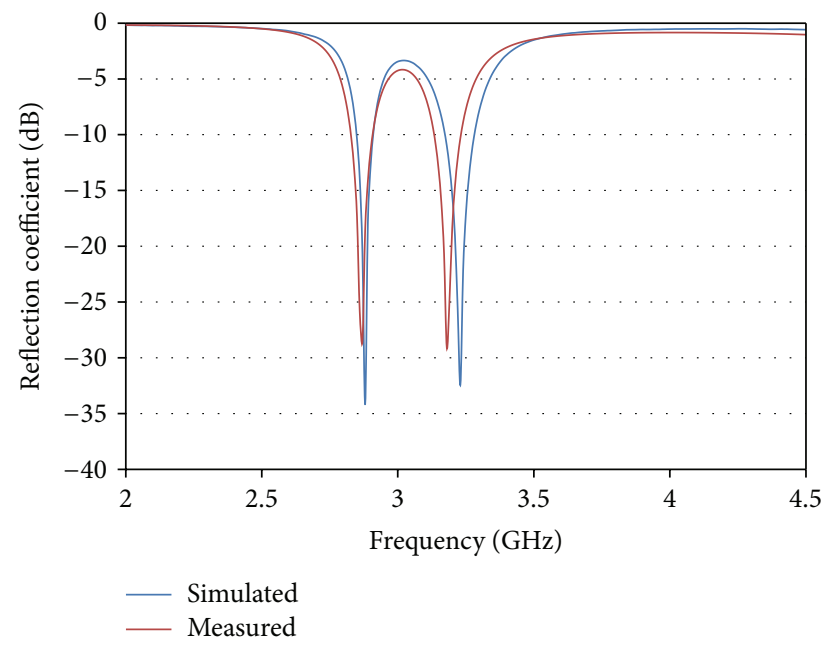

Figure 2: Simulated and measured reflection coefficients for single layered semielliptical patch antenna.

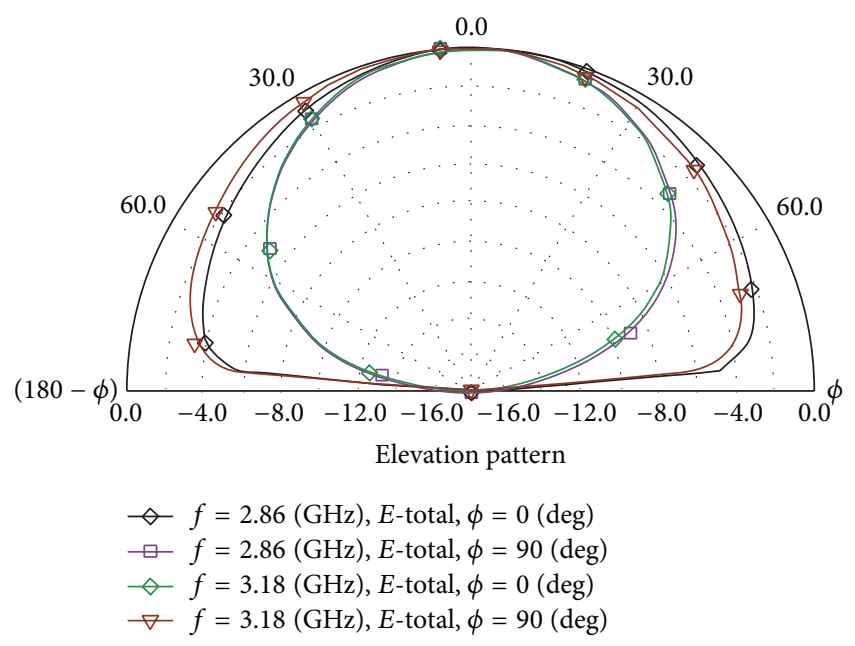

FIGURE 3: Simulated elevation pattern for single layer semielliptical patch antenna. geometry. If the realized performance of proposed semielliptical patch antenna is at par with that of a conventional elliptical patch antenna, a semielliptical patch antenna may prove to be a useful structure for modern wireless communication systems and in radar applications. Later considered semielliptical patch antenna is modified in steps to obtain its improved performance. The prepared antenna is circularly polarized in nature, provides broadband performance, and operates efficiently to cover entire median band $(3.40 \mathrm{GHz}$ to $3.69 \mathrm{GHz}$ ) allocated for WiMAX communication systems.

\section{Antenna Design, Analysis, and Results}

2.1. Single Layer Semielliptical Microstrip Antenna. The work started with an elliptical patch antenna for application in median band of WiMAX communication system. Considering frequency requirements, substrate permittivity, the patch dimensions are selected following $[12,13]$. This elliptical patch antenna with ground plane size $75 \mathrm{~mm} \times 75 \mathrm{~mm}$ is considered on glass epoxy FR-4 substrate having relative permittivity $\varepsilon_{r}=4.4$, thickness $h=1.59 \mathrm{~mm}$, and loss tangent $\tan \delta=$ 0.025 . This semielliptical patch has semimajor axis " $a$ " = $23.0 \mathrm{~mm}$ and semiminor axis " $b$ " $=14.0 \mathrm{~mm}$ and is simulated by using method of moments based IE3D simulation software [14]. Inset feed arrangement using SMA connector is applied for feeding this antenna. The simulation of this geometry indicates that this antenna resonates at frequency $3.40 \mathrm{GHz}$ with impedance bandwidth $80 \mathrm{MHz}$. Looking at narrow impedance bandwidth and size requirements, this antenna was converted into semielliptical patch with same " $a$ " and " $b$ " values and inset feed arrangement is selected for feed purpose as shown in Figure 1(b). The fabricated antenna for experimentation is shown in Figure 1(a). The simulated and measured variations of reflection coefficient $\left(S_{11}\right)$ of semielliptical patch antenna as a function of frequency are shown in Figure 2, which indicates that antenna is resonating at two closely spaced frequencies $2.86 \mathrm{GHz}$ and $3.18 \mathrm{GHz}$ with impedance bandwidths close to $75 \mathrm{MHz}$ and $90 \mathrm{MHz}$, respectively. The measured resonant frequencies of this antenna 


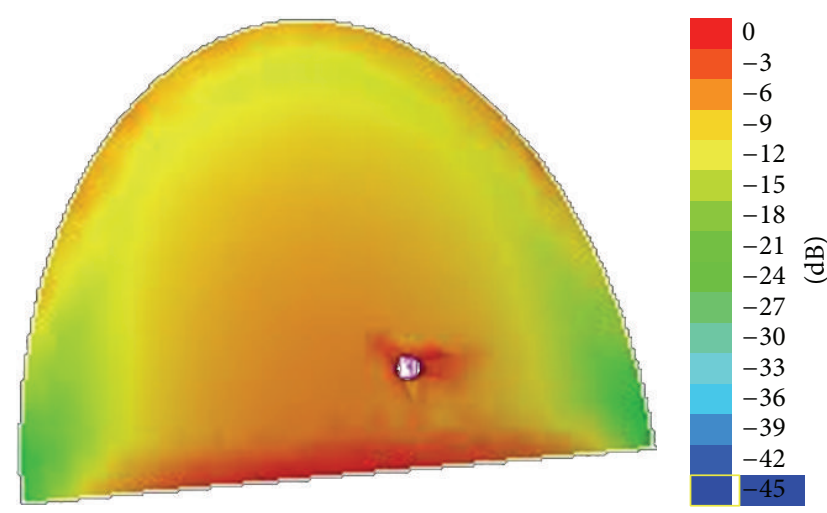

(a)

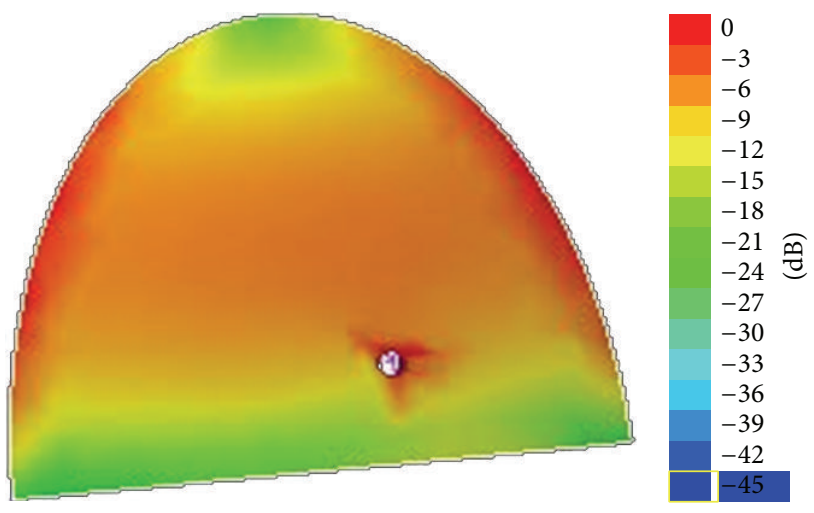

(b)

FIGURE 4: (a) Current distribution on patch at frequency 2.86 GHz. (b) Current distribution on patch at frequency $3.18 \mathrm{GHz}$.

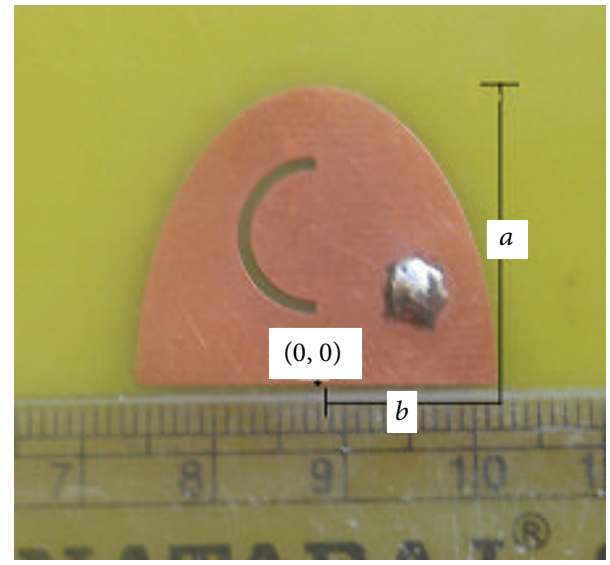

FIGURE 5: Top view of semielliptical patch antenna structure with semicircular ring slot.

are $2.88 \mathrm{GHz}$ and $3.24 \mathrm{GHz}$, respectively, with impedance bandwidths close to $70 \mathrm{MHz}$ and $100 \mathrm{MHz}$, respectively.

The simulated and measured impedance bandwidths of this antenna are very narrow (of order of 2-3\%) with respect to central frequencies corresponding to two modes. The antenna gain values at two resonance frequencies are $1.38 \mathrm{dBi}$ and $2.15 \mathrm{dBi}$, respectively, and antenna presents low radiation efficiency. The input impedance and axial ratio variations with frequency indicate that antenna in its present form is linearly polarized in nature. The simulated $E$ and $H$ plane radiation patterns of antenna drawn at two resonance frequencies are shown in Figure 3, which indicates that the patch antenna produces a cardioid pattern along the bore sight. The $3 \mathrm{~dB}$ beamwidths in $E$ and $H$ plane are $160^{\circ}$ and $90^{\circ}$, respectively; hence $H$-plane patterns are more directive than $E$-plane patterns.

The current distribution on patch geometry at the two resonance frequencies is shown in Figures 4(a) and 4(b). At lower frequency $(2.86 \mathrm{GHz})$, the current density maximum near straight edge while at higher frequency $(3.18 \mathrm{GHz})$ current density is higher close to curved periphery of the patch geometry and is sufficiently higher in the intermediate

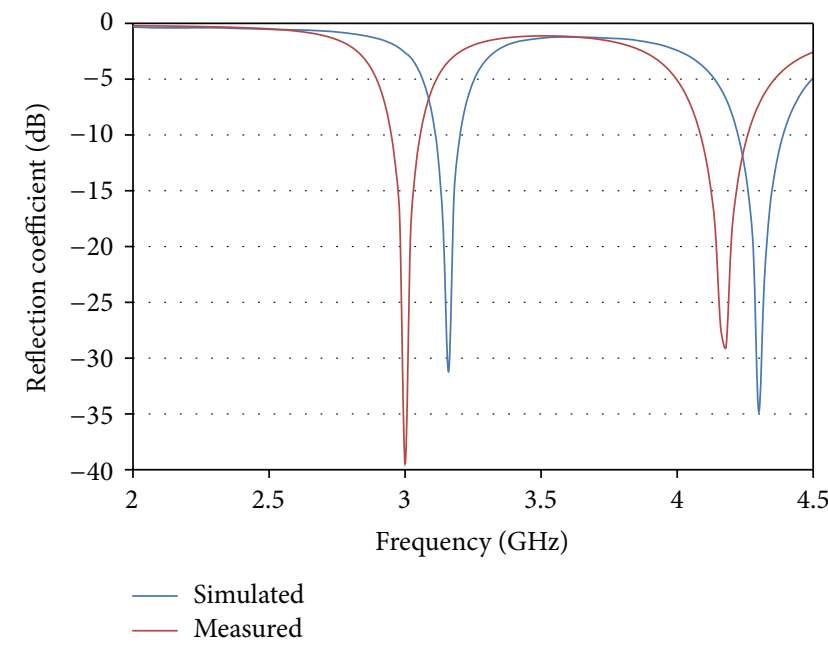

FIGURE 6: Simulated and measured variation of reflection coefficient with frequency for single layer semielliptical patch antenna with semicircular ring slot.

region. On cutting a slot of appropriate dimensions at an appropriate location in this region, the patch current will get sufficiently disturbed and, hence, there is a possibility of improvement in the performance of antenna geometry. These results indicate that impedance bandwidth and gain of antenna of proposed semielliptical patch antenna are quite low; hence, this antenna in its present form is not suitable for practical applications.

\subsection{Semielliptical Patch Microstrip Antenna with Semicircular} Ring Slot. Looking at practical limitation of semielliptical patch and current distribution on patch geometry, this patch radiator is modified by cutting a semicircular ring slot in the patch geometry as shown in Figure 5. Extensive optimizations in inner and outer radii as well as in location of center of semicircular ring slot have been done to achieve improved performance of antenna. The center of finally considered semicircular ring slot is located at $0,11.5 \mathrm{~mm}$ with respect to center of the semielliptical patch while inner and outer radii of applied semicircular ring slot are $5.1 \mathrm{~mm}$ and $6.1 \mathrm{~mm}$, 


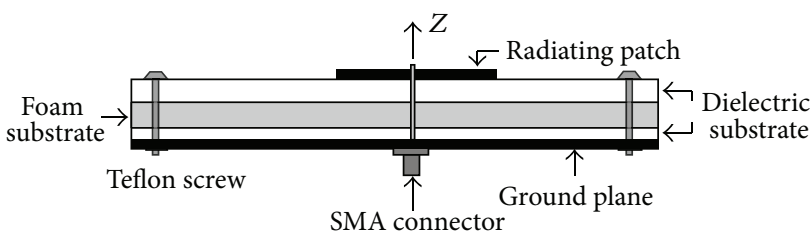

(a)

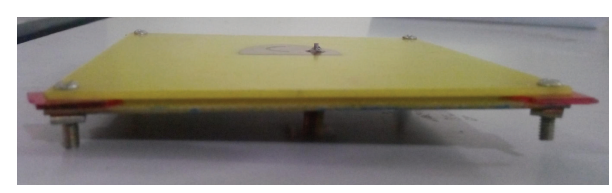

(b)

FIGURE 7: (a) Side view of modified multilayered semielliptical patch antenna with an air gap. (b) Side view of designed modified semielliptical patch antenna with an air gap.

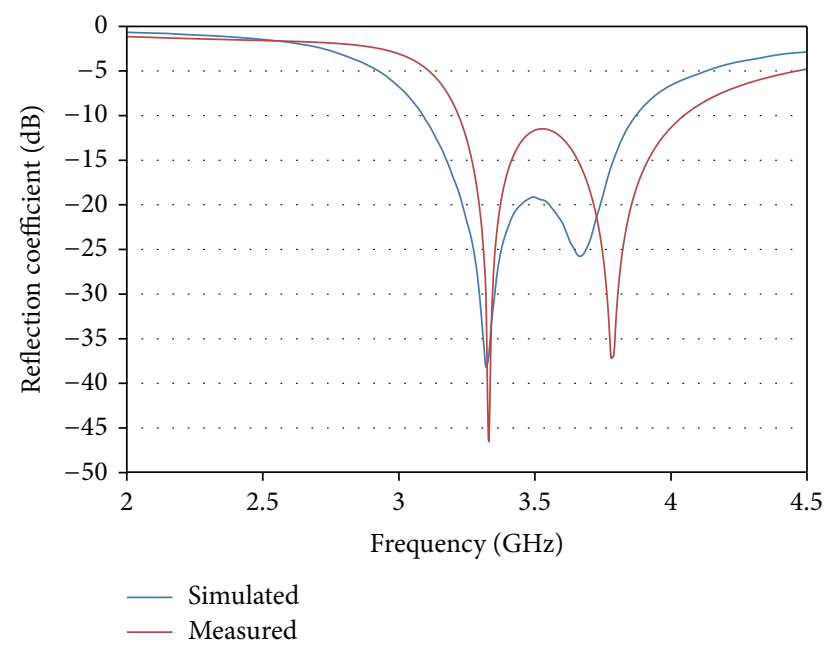

FIGURE 8: Simulated and measured reflection coefficient for proposed antenna.

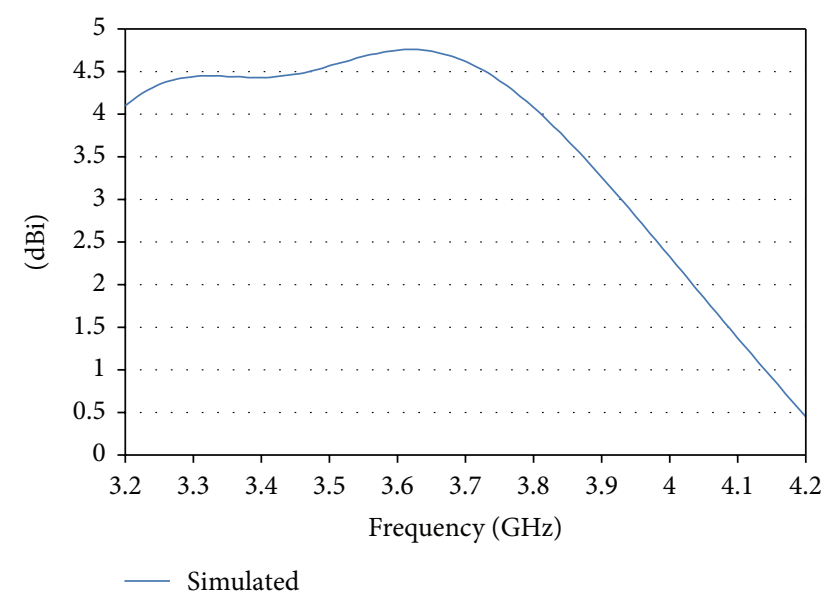

FIGURE 9: Simulated variation of total field gain with frequency for proposed antenna.

respectively. The inset feed point is located at $7.2 \mathrm{~mm}$ and $6.2 \mathrm{~mm}$ with respect to center of the semielliptical patch.

On comparing Figures 2 and 6, we can realize that on introducing semicircular ring in semielliptical patch, the first resonance frequency shifts towards lower frequency side with marginal improvement in impedance bandwidth while

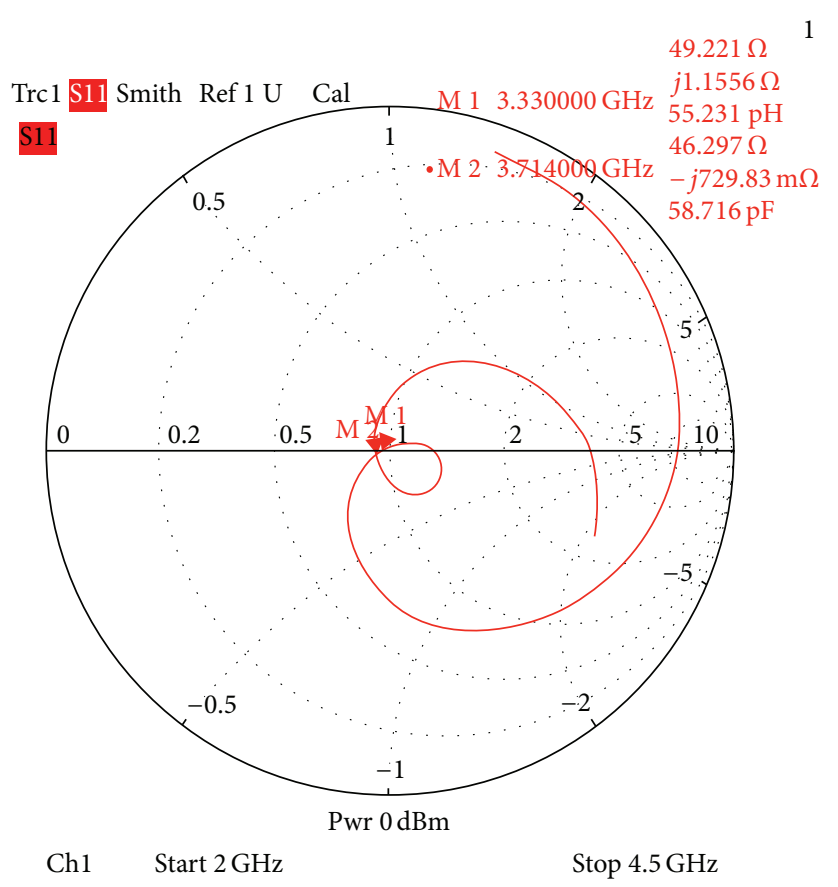

FIGURE 10: Measured input impedance for modified semielliptical microstrip patch antenna.

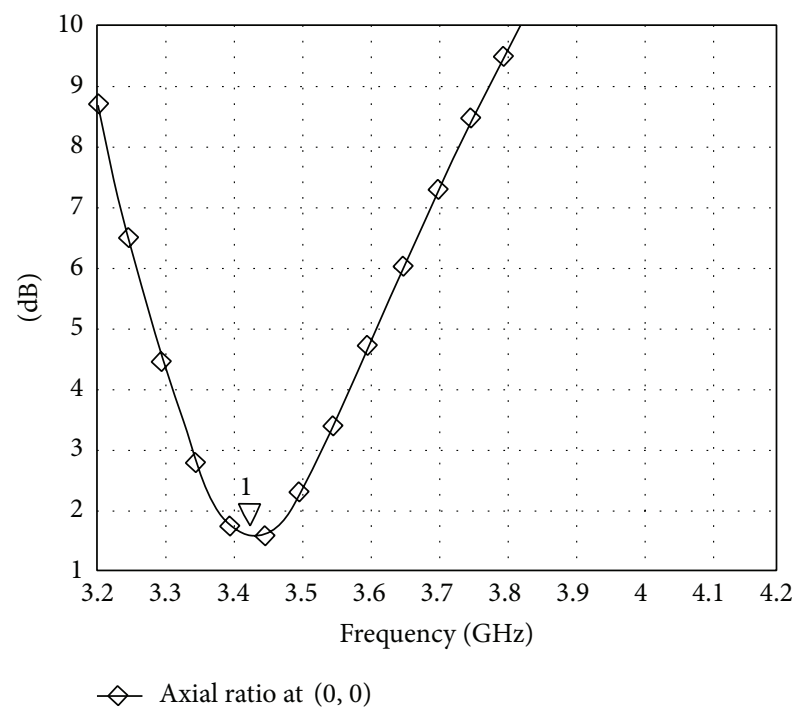

FIGURE 11: Simulated axial ratio with frequency for modified semielliptical patch antenna. 


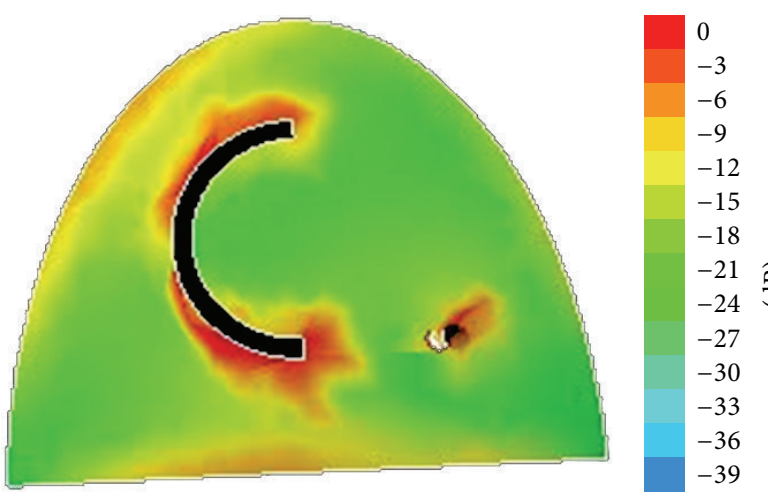

(a)

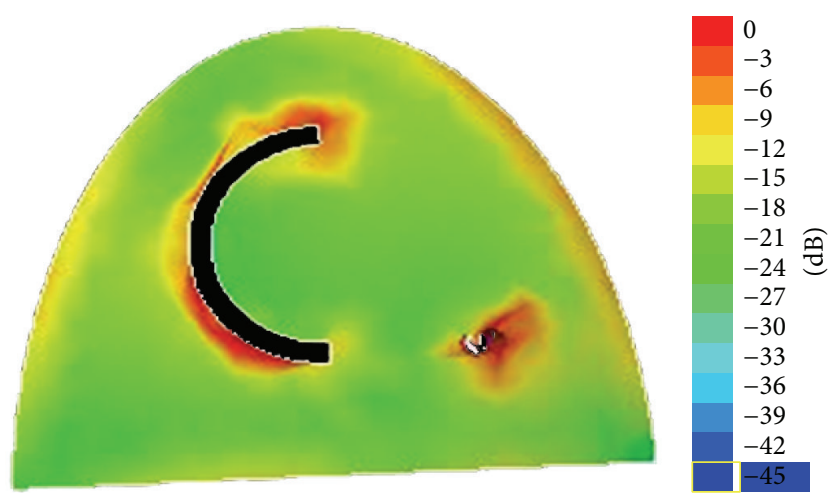

(b)

FIGURE 12: (a) Current distribution on patch at frequency $3.33 \mathrm{GHz}$. (b) Current distribution on patch at frequency $3.78 \mathrm{GHz}$.

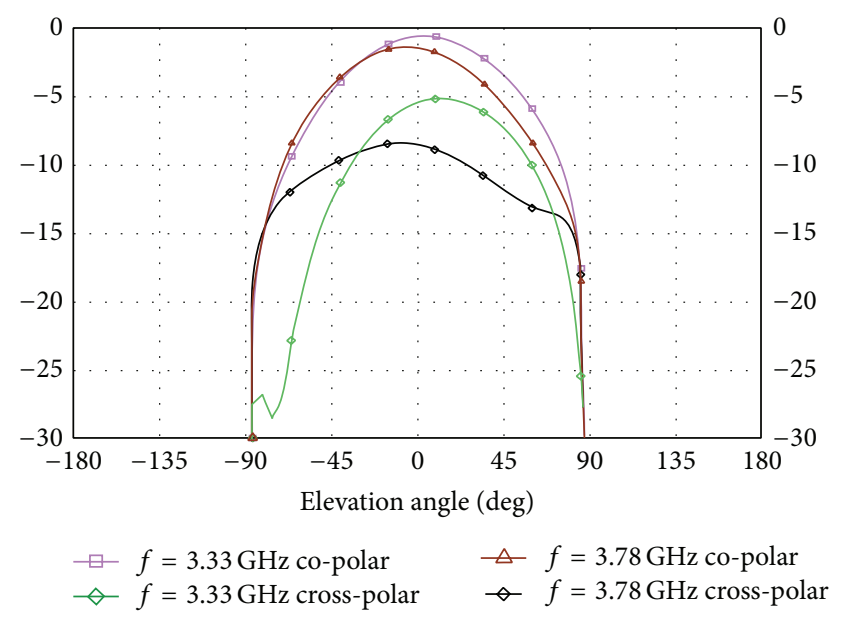

FIGURE 13: Elevation radiation pattern for proposed antenna with annular slot having air gap.

the second resonance frequency remains almost unchanged though marginal improvement in impedance bandwidth is realized. The measured resonance frequencies are $2.59 \mathrm{GHz}$ and $3.17 \mathrm{GHz}$ with impedance bandwidths $80 \mathrm{MHz}$ and $110 \mathrm{MHz}$, respectively. Antenna in its present form is still linearly polarized in nature and simulated gain is still low at the two resonance frequencies $(1.8 \mathrm{dBi}$ and $2.4 \mathrm{dBi}$, resp.). The simulated patterns have cardioid shape and direction of maximum radiations is normal to patch geometry. The performance of this antenna is still not suitable for practical application and, hence, this antenna is further modified by applying multilayered substrates between conducting patch and ground plane.

\subsection{Multilayered Semielliptical Patch Antenna Having Semi-} circular Ring Slot. With the geometry considered in the previous section, achieved impedance bandwidth and gain values of antenna are still low; therefore this antenna is further modified by introducing three layers of substrate material between conducting patch and ground plane. The two glass epoxy FR4 substrates layers separated by thin foam layer (1.0 mm thickness) are put one over the other to enhance antenna performance. The overall thickness of antenna geometry is less than $4.2 \mathrm{~mm}$. All the three layers have overall size $75 \mathrm{~mm} \times 75 \mathrm{~mm}$. No patch is drawn on upper side of lower glass epoxy FR4 substrate while ground plane is not retained on upper glass epoxy FR4 substrate. The side view of proposed antenna is shown in Figure $7(\mathrm{a})$ while fabricated antenna is shown in Figure 7(b). With the present arrangement, the effective permittivity and loss tangent of the substrate material are reduced considerably which in turn lowered the quality factor and enhanced the impedance bandwidth of proposed antenna.

The simulated and measured variations of reflection coefficient with frequency for proposed structure are shown in Figure 8. This indicates that antenna is now resonating at frequencies $3.34 \mathrm{GHz}$ and $3.79 \mathrm{GHz}$. The reflection coefficient curves for the two excited modes are so close to each other that they partially overlap with each other to give large impedance bandwidth. The simulated impedance bandwidth of this modified antenna has approached almost $22.8 \%$ with respect to central frequency $3.64 \mathrm{GHz}$, whereas the measured impedance bandwidth is $21.1 \%$ with respect to central frequency $3.58 \mathrm{GHz}$, which are in close agreement. The proposed antenna covers entire median band 3.40 to 3.69 GHz allocated for WiMAX communication systems. The variation of simulated gain of proposed antenna as a function of frequency is shown in Figure 9, which indicates that gain of antenna in the frequency region of interest is improved considerably. The maximum gain value is $4.6 \mathrm{dBi}$, which is more than twice in comparison with the gain value attained with single layered structure.

In order to obtain circularly polarized (CP) radiations, it is necessary to excite two orthogonal modes with equal amplitude and in phase quadrature. This can be accomplished by slightly perturbing a patch at appropriate locations with respect to the feed. With proposed modifications, the presence of a small loop in the measured input impedance curve of antenna geometry is realized as shown in Figure 10, which indicates the possible presence of circular polarization. This result was confirmed by evaluating the axial ratio of antenna as a function of frequency. Figure 11 shows the 


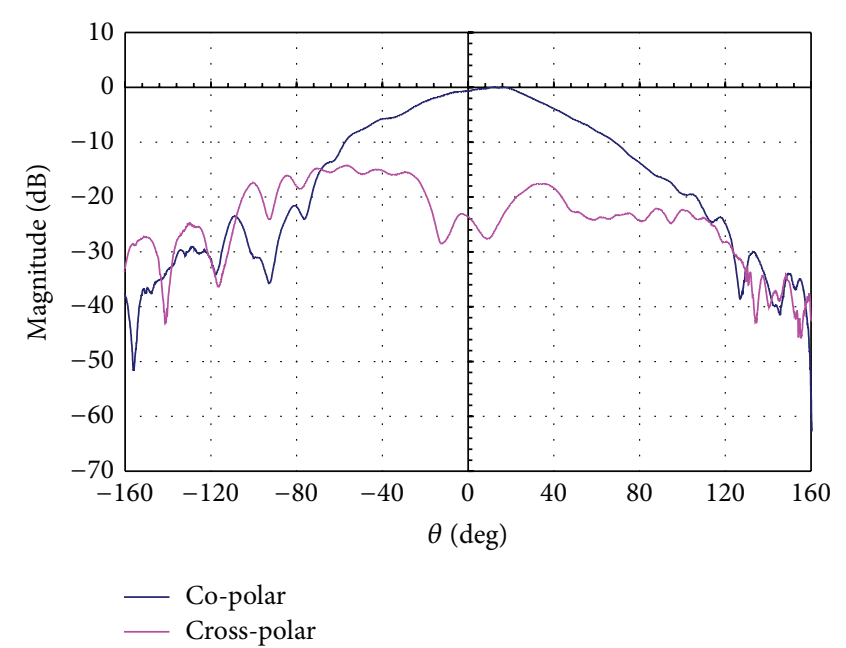

(a)

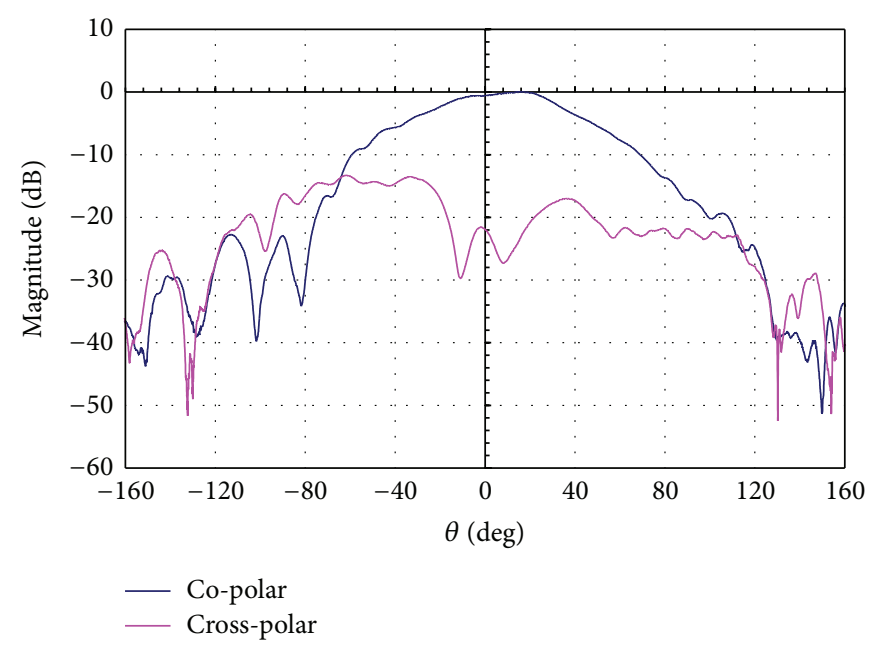

(b)

FIGURE 14: (a) Measured co- and cross-polar patterns at frequency 3.39 GHz. (b) Measured co- and cross-polar patterns at frequency 3.73 GHz.

variation of axial ratio with frequency which depicts that the minimum axial ratio is close to $1.65 \mathrm{~dB}$ with respect to frequency $3.42 \mathrm{GHz}$, while $3 \mathrm{~dB}$ axial ratio bandwidth is close to $5.5 \%$. The minimum axial ratio suggests the requirement of improvement in patch geometry, as for pure circular polarization; the minimum value of axial ratio must be unity.

The current distribution on patch geometry at the two resonance frequencies is shown in Figures 12(a) and 12(b). For both the resonance frequencies, the maximum current density is close to inserted slot. The simulated co- and crosspolar patterns of proposed antenna at both the resonance frequencies are shown in Figure 13. These patterns suggest that in each case, shape of radiation patterns and the direction of maximum radiations in the entire band are almost identical. At frequency $3.33 \mathrm{GHz}$, the cross-polar radiation pattern is nearly $5 \mathrm{~dB}$ down in comparison to copolar pattern, while at frequency $3.78 \mathrm{GHz}$, the cross-polar radiation pattern is nearly $7 \mathrm{~dB}$ down in comparison to copolar pattern. The measured co- and cross-polar radiation patterns of proposed antenna at measured frequency $3.39 \mathrm{GHz}$ and $3.73 \mathrm{GHz}$ are shown in Figures 14(a) and 14(b). At both the frequencies, the direction of maximum radiations is normal to the patch geometry and the copolar patterns are several $\mathrm{dB}$ higher than the cross-polar patterns. The patterns in the present case are more directive than those realized in the previous two cases. The efficiency of antenna also increased considerably as effective loss tangent of substrate material is reduced substantially with insertion of foam substrate between two glass epoxy substrate layers. The radiation efficiency of antenna has approached almost $49 \%$; it was close to $37 \%$ in the first case.

\section{Conclusions}

This paper presents the radiation performance of a modified multilayered semielliptical patch antenna with semicircular ring slot. With proposed modifications, a broad impedance bandwidth of order of $21.1 \%$ is achieved which is nearly ten times higher than that of a conventional semielliptical patch antenna. The gain of antenna is also improved considerably and is more than twice that obtained for a conventional semielliptical patch antenna. The measured and simulated results are in good agreement. Limitations of applied simulation software, fabrication tolerances of antenna, and possibility of misalignment of upper and lower layer patches during fabrication of prototype antenna for experimentation might be responsible for slight difference in simulated and measured impedance bandwidth values. The proposed antenna covers the entire median band of WiMAX systems as per IEEE 802.16 standards. The measured radiation patterns in the entire frequency range of interest are identical in shape and direction of maximum intensity is normal to patch geometry. Though the overall thickness of patch antenna is increased marginally, significant improvement in impedance bandwidth and gain and radiation efficiency of antenna suggests that the proposed antenna may be a useful structure for median band of WiMAX communication systems. Through scale modeling, this antenna may be made compact without much variation in its performance.

\section{Conflict of Interests}

The authors declare that there is no conflict of interests regarding the publication of this paper.

\section{Acknowledgment}

The authors express their sincere thanks to DEIT, New Delhi, for providing financial support for the present work.

\section{References}

[1] K. L. Wong, Compact and Broadband Microstrip Antennas, John Wiley \& Sons, 2003. 
[2] R. Garg, P. Bhartia, I. J. Bahl, and A. Ittipiboon, Microstrip Antenna Design Handbook, Artech House, Norwood, Mass, USA, 2001.

[3] S. A. Long and M. W. Mcallister, "The Impedance of an elliptical printed-circuit antenna," IEEE Transactions on Antenna and Propagation, vol. 30, pp. 1197-1200, 1982.

[4] V. Sharma, V. K. Saxena, K. B. Sharma, and D. Bhatnagar, "Radiation performance of an elliptical patch antenna with three orthogonal sector slots," Romanian Journal of Information Science and Technology, vol. 14, no. 2, pp. 123-130, 2011.

[5] S. A. Long, L. C. Shen, D. H. Schaubert, and F. G. Farrar, "An experimental study of the circular-polarized elliptical printedcircuit antenna," IEEE Transactions on Antennas and Propagation, vol. 29, no. 1, pp. 95-99, 1981.

[6] V. Sharma, V. K. Saxena, J. S. Saini et al., "Wideband dualfrequency right triangular microstrip antenna with parallel narrow slits," Microwave and Optical Technology Letters, vol. 52, no. 5, pp. 1082-1087, 2010.

[7] R. Joseph and T. Fukusako, "Circularly polarized broadband antenna with circular slot on circular ground-plane," Progress in Electromagnetics Research C, vol. 26, pp. 205-217, 2012.

[8] Y. F. Liu, K. L. Lau, Q. Xue, and C. H. Chan, "Experimental studies of printed wide-slot antenna for wide-band applications," IEEE Antennas and Wireless Propagation Letters, vol. 3, no. 1, pp. 273-275, 2004.

[9] P. S. Hall, "Probe compensation in thick microstrip patches," Electronics Letters, vol. 23, no. 11, pp. 606-607, 1987.

[10] D. Guha, "Resonant frequency of circular microstrip antennas with and without air gaps," IEEE Transactions on Antennas and Propagation, vol. 49, no. 1, pp. 55-59, 2001.

[11] V. Sharma and M. M. Sharma, "Wideband gap coupled assembly of rectangular microstrip patches for Wi-Max applications," FREQUENZ Journal RF-Engineering and Telecommunications, vol. 68, no. 1-2, pp. 25-31, 2014.

[12] J. P. Kinzer and I. G. Wilson, "Some results on cylindrical cavity resonators," The Bell System Technical Journal, vol. 26, pp. 410445, 1947.

[13] N. Kumprasert and W. Kiranon, "Simple and accurate formula for the resonant frequency of the circular microstrip disk antenna," IEEE Transactions on Antennas and Propagation, vol. 43, no. 11, pp. 1331-1333, 1995.

[14] IE3D Software Release 14.0 developed by M/s Zeland Software, Inc. 

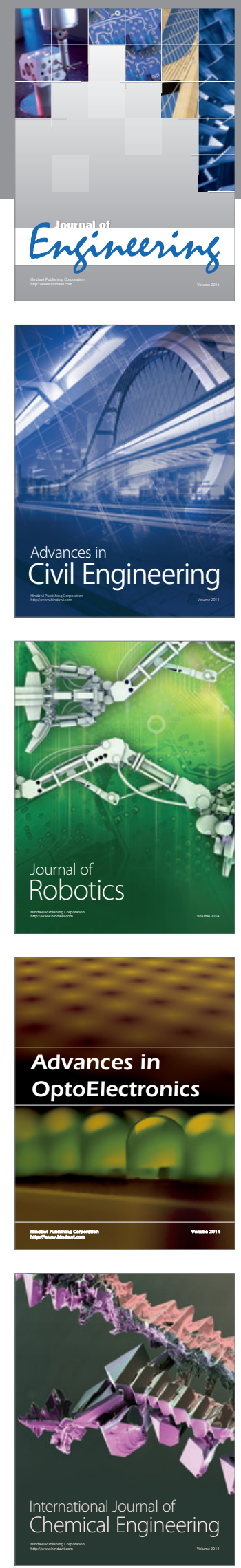

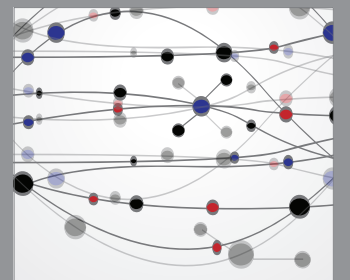

The Scientific World Journal
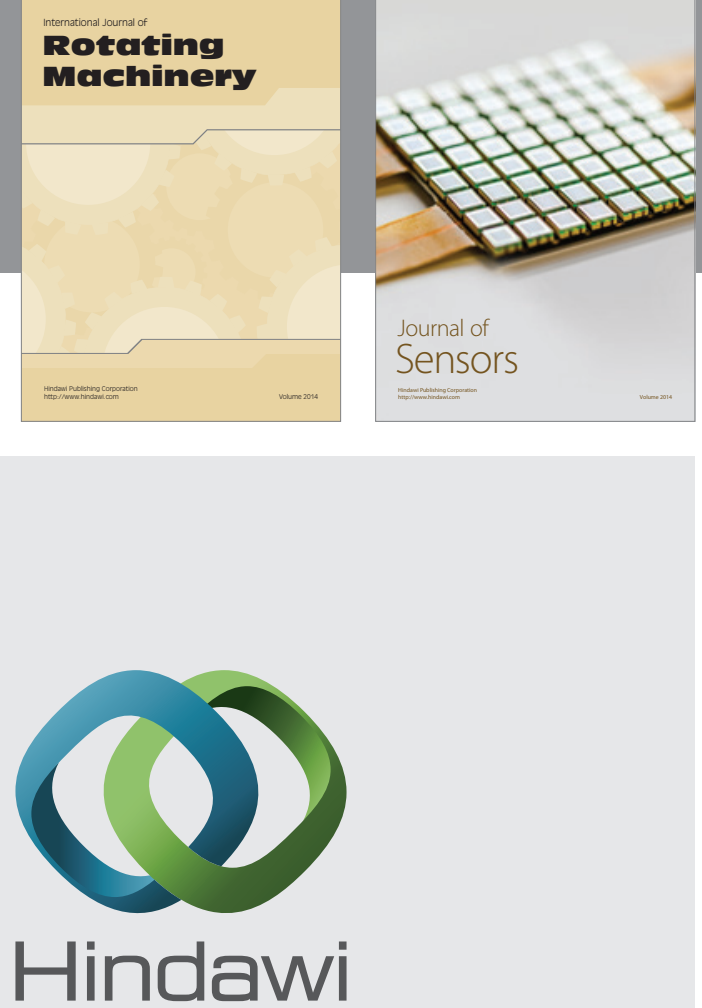

Submit your manuscripts at http://www.hindawi.com
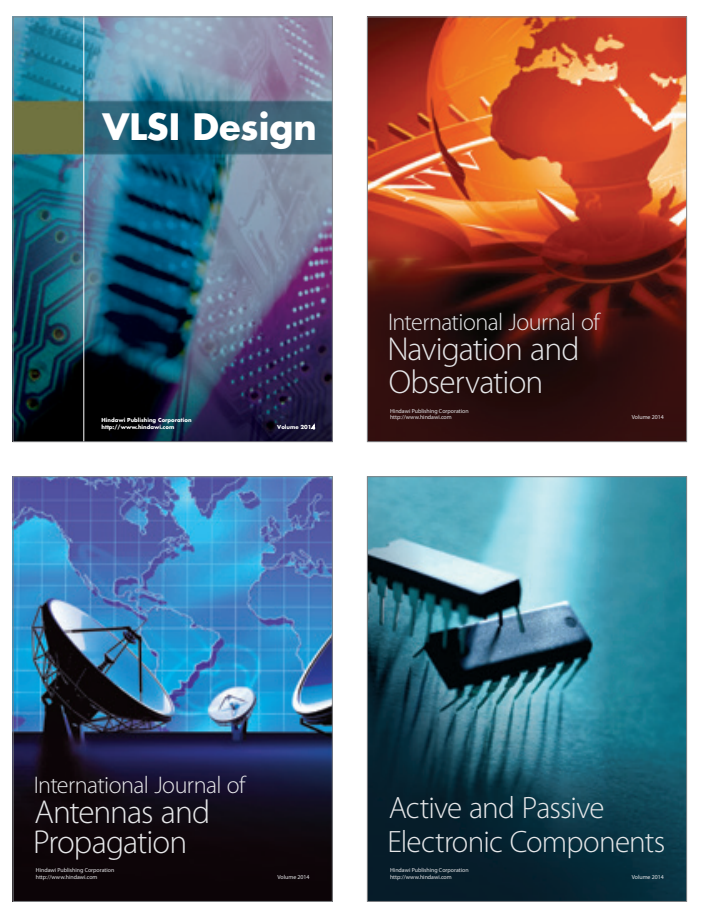
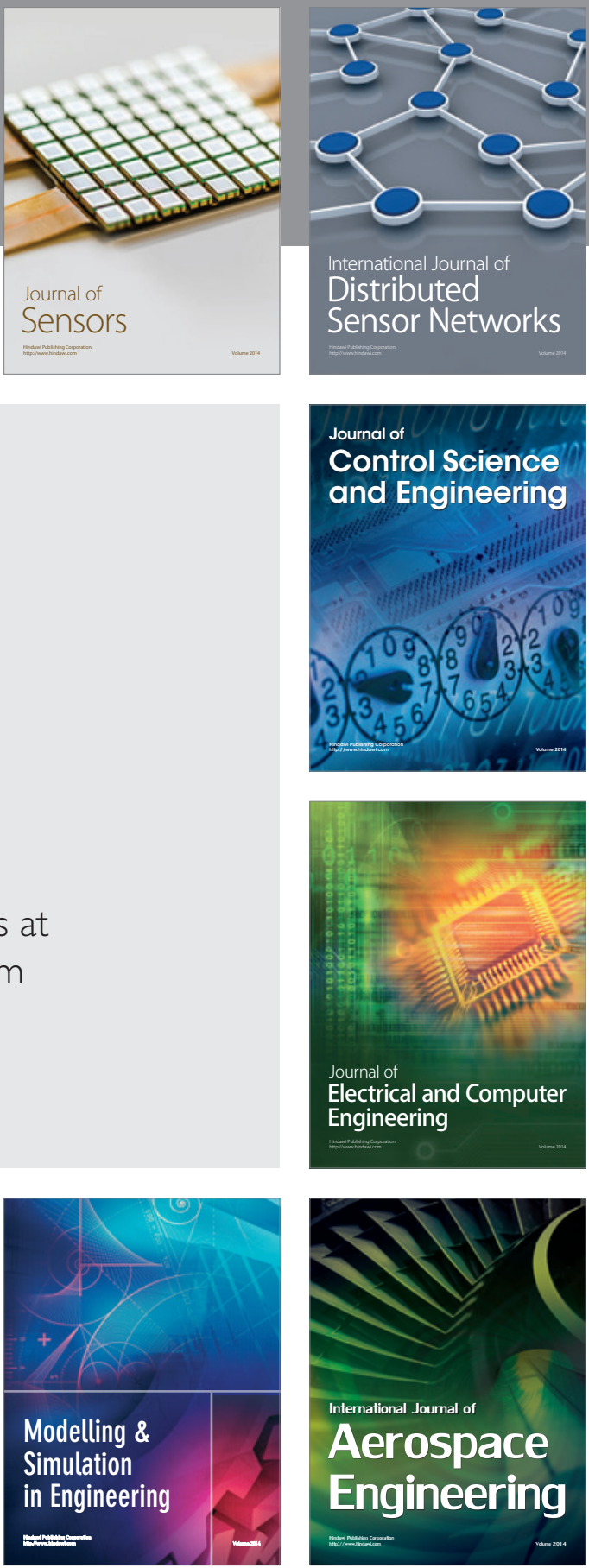

Journal of

Control Science

and Engineering
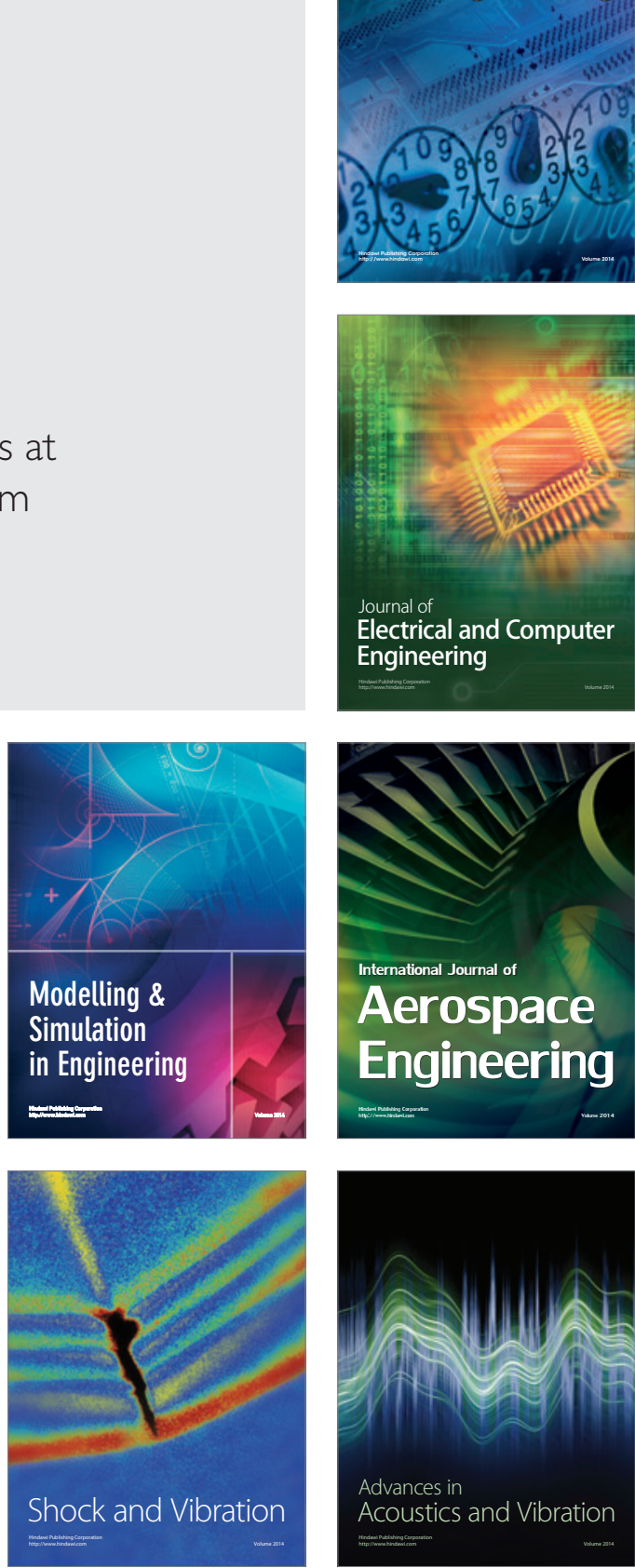